RESENHA A globalização como fábula é apresentada como

Gabriela Fernandes Guimarães - UNESP Maira Franciane da Silva - UNESP

SANTOS, Milton. Por uma outra globalização - do pensamento único à consciência universal. Rio de Janeiro: Record, 2006.

\section{Milton Santos e sua leitura sobre as dores e os problemas do mundo atual}

\section{Introdução Geral}

Milton Santos (1926-2001), bacharel em Direito pela Universidade Federal da Bahia (1948) e doutor em Geografia pela Universidade de Strabourg (1958), foi um pesquisador implicado na realidade local e ao mesmo tempo viajante, com uma carreira internacional de destaque, marcada por seu trabalho como professor, em universidades renomadas pelo mundo.

No Brasil sua carreira foi marcada principalmente pela sua condução paralela entre a vida acadêmica e as atividades públicas, como jornalista e redator. Recebeu inúmeros prêmios, dentre eles o prêmio internacional de Geografia Vautrin Lud em 1994 e foi condecorado com o título de professor Emérito da Faculdade de Filosofia, Letras e Ciência da Universidade de São PauloUSP, acumulando em sua trajetória ainda o título de Doutor Honoris Causa de doze universidades brasileiras e sete universidades internacionais.

Por uma outra globalização, do pensamento único ao universal foi uma de suas ultimas obras, publicada em 2000, onde o autor propõe uma interpretação multidisciplinar do mundo contemporâneo, tratando a globalização como fábula, como perversidade e como possibilidade.

O autor, desde as primeiras linhas da introdução vem com a intenção de fazer uma leitura gradual e analítica do advento da globalização, dividindo-a em três perspectivas: a globalização como fábula, a globalização perversa e a globalização como um vir a ser: uma nova globalização. aquela que é repetidamente publicada pelos meios hegemônicos de comunicação, como uma fase do desenvolvimento econômico prenhe de possibilidades e alternativas para toda a população do mundo. Nesta visão, aconteceu uma ode à informação, colocada como capaz de diminuir distâncias e deixar o conhecimento sobre todos os acontecimentos mundiais ao alcance de nossos olhos. Há ainda a citação da valorização do consumismo, que nessa leitura do globalismo de fábulas, ignora os efeitos cabais dessa ideologia de descontrole das ilusões materiais.

Ao falar da globalização em seu prisma perverso, Santos aponta os desastres relacionados a esta fase de desenvolvimento cindido, onde por um lado é relegado aos pobres e às classes médias parcela caustica dessa forma de sociabilidade, materializada na falta de acesso a bens básicos e que é focada numa forma de produção predatória gradual decréscimo da qualidade de vida daqueles que tiveram algum acesso. $\mathrm{O}$ capitalismo globalizado tem sua face unicamente voltada a gerar grandes lucros para poucos.

Em meio ao mar de informações, a este filão da população é destinada a falta de acesso à educação de qualidade, o subconsumo e a decadência realidade que gera consequências que também são discutidas no decorrer do texto, como a violência, a alteração da percepção do tempo e a anulação das expressões da generosidade nas relações sociais e humanas.

Ao falar sobre a potencialidade da construção de uma nova globalização, Santos une a diversidade social que nasce da exposição à escassez e o acesso aos bons resultados do crescimento inédito dos meios de comunicação, junção que seria capaz de alterar os rumos do progresso e colocalo a serviço de todos que trabalham diariamente para garantir a existência desse sistema, mas que não participa dos ganhos desse suor.

\section{A produção da globalização.}

A globalização tem o início e desenvolvimento no aprimoramento das técnicas e da evolução das ideias políticas, desenvolvimento este que nos primórdios fazia parte da construção dos meios de satisfazer as necessidades humanas de uma forma focada no valor de uso. 
Até o início do século $\mathrm{XX}$, as formas de desenvolvimento das técnicas aconteciam de forma gradual e de acordo com as descobertas de cada região, com o passar do tempo e com o despontar de técnicas mais elaboradas.

Cabe ressaltar que uma determinada técnica continha um conjunto de ferramentas e a evolução desse conjunto toma alcance global quando a tecnologia da informação chega pra vincular o planeta num compasso único, que consideram aqueles com a tecnologia mais avançada como o mais poderoso. Começava a designação de quais países eram a vanguarda e quais tinham formas mais arcaicas de produção.

Em um meio de crescente internacionalização das conexões entre os países. Milton ainda reforça que o desenvolvimento das técnicas de produção e da política sempre fizeram parte do caminhar evolutivo nas nações. Fato novo se fez presente quando o ritmo desse desenvolvimento passou a ser conectado, e as formas de desenvolvimento de ponta afetam de forma mais ou menos perversa cada um dos países - sejam eles tidos como desenvolvidos ou em desenvolvimento.

Essa homogeneização da técnica gerou o advento da competitividade, responsável pelo frenesi de manter-se sempre a frente dos "concorrentes" e destruindo qualquer noção de coletividade em busca de um objetivo comum.

Essa constante perseguição pela melhora das técnicas, unida ao alcance incalculável da informação, geral a pressão homogeneizadora onde os países com o desenvolvimento mais arcaico são influenciados e sugados, obrigados a se adequar aos efeitos de um ritmo que não é compatível com o acumulo de experiencias locais. Milton fala ainda que a junção entre a técnica e a informação trás consigo outro efeito, a percepção do tempo modificada com a sensação da possibilidade de conhecer fatos que estão ocorrendo nos mais diversos locais do planeta. Essa constatação coroada com a indagação sobre quem são as pessoas que de fato são capazes de ter esse acesso ao conhecimento global e quais são os efeitos do aumento a exigência em manterse a par da competitividade global.

\section{Uma globalização perversa}

Fazendo um constante vai-e-vem entre causas e efeitos, Milton foi capaz de expor que esse avanço, apesar de ainda servir à poucos, é um momento inédito na história da humanidade, e que essa mesma tecnologia que desumaniza as relações, também foi capaz de maximizar a capacidade produtiva a ponto de serem criadas novas matérias primas, passiveis de levar a expansão do conhecimento humano à novos patamares de alcance.

Diante do chamado motor único, criador de tanta inovação que se destina a poucos, caminhamos sob a constante sombra da crise, que agora se figura de forma estrutural, dada a conexão entre os modos de produção vanguardistas. Soluções são pensadas, mas estas não conseguem ir além das receitas que já fizeram parte da criação dessa mentalidade restrita aos ganhos financeiros.

Essa forma de desenvolvimento pautadano foco na tecnologia, juntamente ao esquecimento dos limites mais básicos da humanidade, é crescente a reinvenção da violência. $\mathrm{O}$ manejo das mídias pelo poder traz análises que levam em consideração somente as manifestações colaterais da violência, sem momento algum citar que esta forma de sociabilidade globalista causou desespero social inédito. Assim sendo, Milton faz com que seus leitores vejam o quanto é urgente e necessário termos em mente uma percepção crítica capaz de entender o nosso tempo, não caindo nos ardis que culpam aqueles que, em primeiro lugar, são vítimas no caos de evolução perversa e escassa de valores coletivos. Retomando a perspectiva da evolução histórica do desenvolvimento das forças produtivas, Santos nos diz que essa postura de relegar o coletivo no último plano não acontecia nos primórdios das relações humanas, que tinham como base de seu desenvolvimento técnico e relacional o espaço em que habitavam.

O caminhar da história não deve ser entendido de forma linear e simplista, e esta obra traz ainda uma breve análise da influência do desenvolvimento das ideias e costumes, estudados pelos filósofos das Revoluções Francesa e do salto ideológico americano. Pautados na liberdade humana, seja em sua forma individual ou coletiva, os tratados produzidos nos séculos XXI e XX foram capazes de redirecionar a sociedade, recém saída do modo de relações sociais feudais. 
Sem estas revoluções políticas dos idos séculos XXI e XX, a situação atual de nossa sociedade poderia estar ainda mais afundada em concepções materialistas e reificantes.

Outro ponto que tem grande relevância para repensar o patamar em que se encontra a globalização é o estudo da participação do Estado nas relações humanas durante os anos do Pós Primeira e Segunda Guerra mundial e como este foi capaz de mostrar, por um breve período, a sua participação positiva na vida da coletividade, a partir da garantia de direitos e estruturas básicas com foco no desenvolvimento para a população, mesmo que de forma restrita a países de culturas mais antigas.

Nesse interim, aos países historicamente explorados, ficou a noção de uma cidadania jamais alcançada, onde os efeitos da globalização atingem mais profundamente e onde a informação e o acesso ao global é alcançado por uma população mínima. O Brasil e sua vulnerabilidade no campo é um exemplo de como a globalização é capaz de caber em qualquer situação onde enxergue potencialidade pro lucro. Considerando a história brasileira pautada em revoluções "de cima para baixo" e falta de compartilhamento das formas de poder, os efeitos da globalização tem uma das maiores expressões na continuidade da tradição agrário-exportadora, tornando o campo ainda mais cruel para a população que lá habita.

Partindo disso, o livro segue com a exposição da relação da globalização, do dinheiro e do território e como se dá essa relação quando pensada suas consequências no âmbito local.

\section{O Território do Dinheiro e da Fragmentação}

Santos coloca em tela a imprescindibilidade de analisar as questões administrativas dos municípios e estados para além das questões financeiras, propondo uma análise que busque as necessidades locais sem o viés coisificante e atropelado que a globalização impõe. Essa visão não tira por completo a função monetária, apenas realoca sua importância, priorizando o desenvolvimento centrado na realidade da população que em cada espaço habita.

Dessa forma, o autor apresenta o dinheiro e o território como um ambiente de disputas e embates. O território para ele seria a base do trabalho e do pertencimento da população, enquanto o dinheiro seria apenas uma invenção, que surgiu em decorrência de uma atividade econômica, onde se torna indispensável e concede valor a tudo aquilo que pode ser considerado objeto de comércio, sobrepondo inclusive à vida social.

Consequentemente, as relações sociais são diretamente afetadas, criando uma interdependência entre as sociedades antes isoladas, tornado o dinheiro instrumento de regulação da vida social. Dessa forma, o território passa a ser uma arena de movimentos, fundada sobre uma lei de valor, e o dinheiro vai se tornando cada vez mais essencial, aumentando a complexidades das relações, instituindo uma relação de categorias interdependentes caracterizadas como Estado territorial, nacional e internacional.

Com a globalização, o uso do dinheiro é permitido através de técnicas existentes e disponíveis, que instala um dinheiro fluido, autonomizado e universal. Isso, Santos chamaria de contabilidade global, cuja base seria um conjunto de parâmetros que os governos globais utilizam para classificar as economias nacionais, fazendo do dinheiro autonomizado, o principal regente do território.

O autor nos apresenta também a ideia de verticalidades e horizontalidades. As verticalidades segundo ele seriam definidas no território, como um conjunto de pontos que formam um espaço de fluxos que poderia ser caracterizado também como um subsistema dentro da totalidade-espaço. Neste modelo econômico, constituído por um sistema de redes e composto por macroempresas que regulam o conjunto de espaços, fazendo com que mantenha uma regulação subordinada, favoreça atores hegemônicos e mantenha uma integração que seria vertical e ao mesmo tempo alienadora, considerando que suas decisões essenciais relacionadas aos locais, seriam estranhas ao lugar, obedecendo motivações distantes, ou seja, Santos nos esclarece que a construção do destino de uma área é entregue aos interesses privados de uma determinada empresa, que não tem compromisso com a sociedade local, fazendo com que quanto mais modernizados por essa lógica vertical, mais alienados os espaços se tornam.

As horizontalidades formam, segundo o autor, 
extensões contínuas, do qual ele se apropria da terminologia utilizada pelo economista francês François Perroux, "espaço banal", que seria o espaço de todos, onde fosse possível a existência de uma solidariedade orgânica, com o conjunto sendo formado pela existência comum dos agentes exercendo sobre um território comum. Nesta realidade a ação do Estado é limitada, com uma produção local solidária, obtida mediante solidariedades horizontais internas, ou seja, Santos, diz que a sobrevivência do conjunto depende do exercício da solidariedade, se tornando indispensável ao trabalho e gerando o interesse comum. É neste espaço banal, que segundo o autor se recria a ideia e o fato da Política se tornar necessária, para ajustamentos necessários ao funcionamento do conjunto dentro de um território.

$\mathrm{Na}$ busca por um sentido nessa lógica entre verticalidades e horizontalidades, o autor nos coloca que o território portanto não é apenas um lugar de uma ação pragmática e seu exercício comporta sentimentos, e se torna um abrigo.

Nesta multiplicidade de situações trazidas com a globalização, Santos cita a esquizofrenia do lugar, onde segundo ele ao mesmo tempo em que os vetores da globalização se impõe para estabelecer uma nova ordem, de outro lado eles produzem uma contra-ordem, porque há uma produção acelerada de pobres, excluídos e marginalizados, e sua resolução se dá a partir do fato de que cada pessoa, grupo ou instituição, realiza o mundo a sua maneira.

\section{Limites à Globalização Perversa}

Agora adentraremos nos limites que Santos nos coloca e denomina como globalização perversa. Segundo ele estamos vivendo uma verdadeira fase de transição para um novo período histórico, onde se observa uma expansão acelerada do que ele chama de reino da escassez, que atinge as classes médias, criando mais pobres, com nível de consciência de sua condição cada vez maior. No entanto, ao mesmo tempo, uma boa parcela da população não é mais capaz de obedecer às leis e normas, e cria-se um misto de conformidade com produção de consciência.

A velocidade é colocada por ele como um dado importante na produção na história, no entanto a forma como as pessoas vivem ainda é divergente e o acesso a essa velocidade é restrito, fazendo com que a minoria seja representada pela totalidade, simplesmente pela força do imaginário de se pensar que todos acessam a tudo de forma igualitária.

Com a globalização, o mercado externo exige instigado pela competitividade, o amento da velocidade, criando as crises atuais, que se mostram resultante da aceleração contemporânea, mediante o uso segundo Santos, de privilégios por alguns atores econômicos. Dessa forma, podemos pensar segundo ele que é possível pensar em uma outra globalização, em outro mundo, no entanto o problema central estaria em retomar o curso da história e recolocar o homem no seu lugar central.

O autor nos apresenta também, a ideia de artifício, onde vivemos todos num emaranhado de técnicas, no entanto essas técnicas nos levam a escassez. O autor nos traz isso de forma tão brilhante, que se tornar impossível não citá-lo diretamente. Na medida em que as técnicas
hegemônicas, fundadas na ciência e
obedientes aos imperativos do mercado,
são hoje extremamente dotadas de
intencionalidade, há igualmente
tendência à hegemonia de uma produção
'racional' de coisas e de necessidades; e
desse modo uma produção excludente
de outras para essa orgia de coisas e
necessidades que impõe relações e
nos governam. Cria-se um verdadeiro
totalitarismo tendencial da racionalidade
- isto é, dessa racionalidade hegemônica
dominante-, produzindo-se a partir do
respectivo sistema certas coisas, serviços
relações e ideias. (SANTOS, 2001, p.
128)

Segundo o autor essa seria a primeira produção de carências e escassez, considerando que uma parcela significativa da sociedade não tem acesso a coisas, serviços e ideais que compõe a realidade hegemônica, e revela três tendências que ele denomina como produção acelerada e artificial de necessidades; incorporação limitada de modos de vida ditos racionais e uma produção limitada de carência e escassez. Assim, as técnicas e a velocidade seriam potencializadoras de desigualdades e necessidades, porque não se consegue atingir uma satisfação para todos, ou seja, o que é produzido, necessária ou desnecessariamente é desigualmente distribuído. 
O nosso tempo também passa a ser contabilizado nesse processo, se consagrando multiplicador dessa escassez, seja pelo numero gigantesco de produtos no mercado, seja pelo chamado constante ao consumo. Para os pobres essa realidade se coloca ainda mais difícil, pois se torna um dado permanente da existência, e o trabalho passa a ser um lugar de descoberta cotidiana e de um combate cotidiano, sendo uma ponte entre a necessidade e o entendimento.

Os pobres em contrapartida criam sua própria política de sobrevivência, baseada em um cotidiano vivido por todos, pobres e não pobres, e é alimentada diariamente pela necessidade de continuar existindo.

$\mathrm{O}$ autor traz em sua reflexão também, o aumento da de classe média em decorrência da explosão urbana, e a explosão do consumo e de crédito, tendo relação estrutural com o aumento da produção agrícola e industrial.Segundo ele a classe média é a maior beneficiária do crescimento econômico, do modelo político e dos projetos urbanísticos adotados pela globalização. No entanto, com a diminuição consequencial de acesso a bens e serviços antes assegurados, a classe média passa a viver e reconhecer a experiência da escassez, colocando sobre eles um novo dado na vida social e política.

\section{A Transição em Marcha}

Novos tempos vem surgindo, e com eles a humanidade passa a ser afetada direta ou indiretamente pelo processo de globalização, e para se entender esse processo Santos nos apresenta a existência da técnica informacional, que vem construir elo com outras técnicas na busca pela compreensão da história, utilizandose também da política para concluir essa análise.

Através da globalização acontece uma ressignificação da cultura, em decorrência da influencia da cultura de massas, imposta pelo mercado, que tenta impor-se sobre a cultura popular, onde os mais pobres, não dispõem de meios para acessar a cultura de massas, no entanto produzem e se alimentam de sua própria cultura, expressa e determinada através das relações sociais do território.

Para a concretização de uma outra globalização, Santos ressalta a necessidade de centralizar todas as ações no homem, fugindo da atual conjuntura em que tudo gira em torno do dinheiro, distorcendo o sentido da vida em todas as suas dimensões. A globalização atual tem deixado de lado as políticas sociais e priorizando o uso dos recursos públicos para incorporação e manutenção de países na onda globalitária, gerando consequentemente uma baixa qualidade de vida e aumento no porcentual de população pobre em todos os continentes.

Mas, Santos nos afirma de forma contundente, que para que mudanças sejam possíveis, e consigamos alcançarmos uma outra globalização, essas mudanças saíram dos países subdesenvolvidos. Será através da valorização do individuo e através do processo de tomada de consciência (que acontece de forma e velocidade diferente para cada pessoa), e através da mistura de povos, raças, culturas e religiões, que poderá nos permitir a implantação de um novo modelo econômico, social e político e de um nova forma de distribuição de bens e serviços, conduzindo a realização de uma nova vida solidária e coletiva, que asseguremos uma reforma do mundo, e consequentemente uma nova forma de realizar a globalização.

Esse mundo complexo marcado pela materialidade, se dá devido a forma com a qual a ideologia penetra objetos e ações, e sua totalidade mundo se manifesta pelas unidade das técnicas e das ações. Tudo hoje que existe constitui uma perspectiva de valor, e valem pela sua constituição, ou seja, valem pelo que podem oferecer.

Finalizando sua analise, Santos nos coloca que a globalização não é irreversível. Para ele uma nova história universal verdadeiramente humana está começando, e que a mesma materialidade citada tantas vezes como perversa no decorrer da obra, pode vir a ser a condição de uma construção de mundo mais humano, basta que a mutação tecnologia e a mutação filosófica se completem, de forma democratizada, e possam atribuir um novo sentido a existência de cada pessoa e também do planeta.

\section{Conclusão}

O tema trazido por Milton Santos é capaz de fomentar discussões acerca da atual fase de desenvolvimento do capitalismo globalizado 
sobre os aspectos políticos, financeiros e sociais, e sua complexidade é capaz de ser inserida nas mais diversas áreas de pesquisa e sua proposta de integração da população em nível local inova nas proposições anseiam por soluções para as mazelas do atual modo de sociabilidade.

Após discorrer sobre a decadência da generosidade, estrangulada pela competitividade estimulada pelo pensamento único, nota-se que é a partir do momento de maior descrença e crise que é possível vislumbrar novas soluções, indo além das informações produzidas pelos meios de produção hegemônico e voltando o olhar para a localidade, o território.

Assim sendo, cabe aos estudiosos a iniciar um movimento em busca de novas formas de relações sociais e outras formas de desenvolvimento, a apropriação do conceito de território, utilizando dados a fim de construir estratégias que superem indicadores genéricos, particularizando e potencializando características coletivas, capazes de modificar os rumos da sociedade em suas bases locais - deixando de reproduzir impensadamente as formas de reprodução do conhecimento impostas de cima para baixo.

O trunfo da possibilidade da mudança já existe, e será a partir da alteração na forma como lidamos com os sistemas globais de informação. Existe uma infinidade de informações que se compartilhadas e utilizadas a partir de concepções coletivos de mundo, analisadas e construídas com a análise do local, as mazelas do dia a dia serão sanadas em uma reação em cadeia.

Por fim, temos a consciência de que somos inseridos em um mundo além do ideal, e que solução definitiva das dificuldades da humanidade está intimamente ligada à alteração e redistribuição das forças produtivas, uma revolução nas bases distributivas de bens e esse caminho começa a ser traçado quando a população se vê imbuída da consciência de qual o rumo que deve-se tomar para tomar o poder de decisões políticas, sociais e materiais.

\section{Referências}

SANTOS, Milton. Por uma outra globalização - do pensamento único à consciência universal. Rio de Janeiro: Record, 2006.

\section{Sobre as autoras}

Gabriela Fernandes Guimarães - Mestranda do Programa de Pós Graduação de Serviço Social da Universidade Estadual Paulista "Júlio de Mesquita Filho" UNESP. Especialista em Gestão Pública pela Universidade Federal de São João del Rei.E-mail: gabriela.assistsocial@gmail.com

Maira Franciane da Silva - Mestranda do Programa de Pós Graduação em Serviço SocialUniversidade Estadual Paulista Júlio de Mesquita Filho- UNESP Campus de Franca

Recebido em: 05/04/2019

Publicado em: 13/07/2019 